\title{
Revista Brasileira de Geriatria e Gerontologia: somando conhecimento e unindo esforços
}

\section{Brazilian Journal of Geriatrics and Gerontology: adding knowledge and joining efforts}

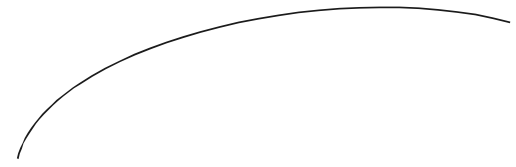

É inegável que a literatura científica brasileira vem dando maior foco às questões de saúde e sociais dos idosos nos últimos anos. Todavia, a assistência dos serviços de saúde para atender a essa clientela está muito longe das necessidades deste segmento populacional, apesar de estar sendo estimulada nos últimos anos, sob diretrizes do Ministério da Saúde.

Apesar do novo redirecionamento, as políticas de saúde para o idoso ainda são pouco estruturadas e disseminadas no campo da saúde pública, inexistindo uma rede de cuidados que ligue a família a serviços de suporte social e de atenção à saúde de base comunitária.

Atualmente, existe um esforço em incorporar os cuidados ao idoso na rede de atenção básica do país, estimulando práticas preventivas e de promoção da saúde. No entanto, ainda há muito a se avançar, não só na incorporação deste conhecimento pelas equipes de saúde da atenção básica, como também na sensibilização de outras instâncias, tais como: ambulatórios especializados, rede de atenção básica, capacitação da assistência social, criação de conselhos tutelares, estruturação das instâncias jurídicas e de educação. Também é ainda precária a compreensão dos profissionais que lidam com idosos em todos os níveis de atenção, a respeito dos problemas de saúde nessa fase da vida.

Este número da Revista Brasileira de Geriatria e Gerontologia reúne 12 artigos de autores que estudam e têm experiência na temática apresentada, oferecendo ao leitor uma visão abrangente e aprofundada de vários temas no campo do envelhecimento humano: a incontinência urinária em mulheres no período pós-menopausa; saúde bucal; deglutição de idosos; composição corporal de idosos; a influência do exercício físico no perfil lipídico e na aptidão física em mulheres idosas; 
a influência do exercício físico em idosos com relação a equilíbrio, marcha e atividade de vida diária; modelos de família entre idosos; qualidade de vida em idosas ativas; condições de saúde e sociodemográficas de idosos residentes em domicílio; influência de fatores nas quedas de idosos; e a sexualidade dos idosos nos textos gerontológicos.

São nove artigos originais, um artigo de revisão e um artigo de atualização provenientes de pesquisadores de sete estados brasileiros (RS, SP, PR, PI, RJ, BA, PE). Há também a contribuição de pesquisadores de duas universidades portuguesas em um artigo de reflexão sobre a Ética e Deontologia na Gerontologia. Assim, a RBGG procura fazer a sua parte, no sentido de contribuir para mostrar que, somando conhecimento e unindo esforços, é possível e construir um novo modelo de assistência mais abrangente e sensível às necessidades dos idosos.

Célia Pereira Caldas Editora Associada 